\title{
Might Cardiac Catheterization Influence Diurnal Rhythm of the Steroid Stress Hormones Secretion?
}

\author{
H. SKARLANDTOVÁ ${ }^{1}$, M. BIČÍKOVÁ ${ }^{2}$, P. NEUŽIL $^{3}$, M. MLČEK ${ }^{1}$, V. HRACHOVINA ${ }^{1}$, \\ T. SVOBODA ${ }^{1}$, E. MEDOVÁ ${ }^{1}$, J. KUDLIČKA ${ }^{1}$, A. DOHNALOVÁ ${ }^{1}, \breve{S}_{\text {. HAVRÁNEK }}^{4}$, \\ H. KAZIHNÍTKOVÁ ${ }^{2}$, L. MÁČOVÁ ${ }^{2}$, E. VAŘEJKOVÁ ${ }^{1}$, O. KITTNAR ${ }^{1}$ \\ ${ }^{1}$ Institute of Physiology, First Faculty of Medicine, Charles University in Prague, Czech Republic, \\ ${ }^{2}$ Institute of Endocrinology, Prague, Czech Republic, ${ }^{3}$ Cardiology Department, Na Homolce \\ Hospital, Prague, Czech Republic, ${ }^{4}$ Second Department of Internal Medicine, Department of \\ Cardiovascular Medicine, First Faculty of Medicine, Charles University and General University \\ Hospital, Prague, Czech Republic
}

Received April 7, 2011

Accepted October 27, 2011

On-line December 20, 2011

\section{Summary}

Glucocorticoids (GCs) are steroid hormones produced by the adrenal cortex in reaction to stress stimuli. GCs production is not stable over a 24-hour period; the plasma concentration peaks in the morning (approximately upon awakening) and then the plasma levels decrease, reaching the nadir in the evening. In our experiments, the levels of cortisol, cortisone, DHEA and DHEAS were tested in young female pigs $(n=23)$ during heart catheterization at two different day times (in the morning and in the afternoon). The non-parametric Mann-Whitney test for statistical analysis was used. We found only minimal statistical differences in studied markers between the morning and afternoon group ( $p>0.05$ ). The absence of circadian variation in GCs levels could originate either at an early age of our experimental pigs, or in stressful conditions on the experiment day, or most likely the day before (e.g. social isolation, fasting, transport, and catheterization), respectively. We can conclude there is no difference in the stress load between morning and afternoon experiments, and therefore we can assume the stress load is not a limiting factor for the timing when catheterization should be preferably performed.

\section{Key words}

Cortisol • Stress • Heart catheterization • Circadian rhythm

\section{Corresponding author}

Kittnar O., Institute of Physiology, First Faculty of Medicine, Charles University in Prague, Albertov 5, 128 00, Prague 2, Czech Republic. E-mail: otomar.kittnar@If1.cuni.cz

\section{Introduction}

Stress has been intensively discussed for many years, not only in human medicine, but also in veterinary medicine and in zoological branches. The term "stress" was used for the first time by Selye (1936), who had described general adaptation syndrome. Stimuli affecting the homeostasis of an organism are called stressors. Stressors could be of many different origins, e.g. ecological (acute environmental changes, nutrition or shelters absence, temperature variations), sociobiological (unstable social hierarchy), health (fever, infection, injury, surgery), transport and many others. Stressors trigger stress response - a complex of physiological, endocrine, metabolic and behaviour reactions protecting organism prior to the injurious effect of stressors (emergency life-history) (Schreiber 1985, Greenberg et al. 2002, Möstl and Palme 2002). These reactions are conservative and proceed in most animal species and human in the same way (Breuner and Orchinik 2002, Greenberg et al. 2002, Romero 2004).

\section{Glucocorticoids}

GCs (main GC in mammals is cortisol, except some rodent taxons, where it is replaced by corticosterone) are steroid stress hormones with 21 carbons, products of adrenal cortex. GCs have an important role in metabolism, especially glucose, and its 
control.

GCs are small lipophilic molecules; nevertheless only those with a hydroxy group on C-11 (cortisol) are biologically active. The lipophilic character of the unbound GCs allows free entry to the target cells through cell membranes to cytoplasm where they are bound to specific receptors. The GC-receptor complex then enters the nucleus and identifies glucocorticoid response elements (GREs), special palindromic DNA sequences, binds to them and acts as a transcription modulator (Seckl 1997).

Cortisone is a steroid hormone produced by the adrenal cortex. The hormone is characterised by the ketogroup on $\mathrm{C}-11$ in its chemical structure. In contrast to cortisol, it cannot be bound to cytoplasmatic receptors due to its different chemical structure. Cortisone could be considered to be an inactive form of cortisol, but, on the other hand, it represents cortisol's reserve pool in the time when more GCs are needed (e.g. in stress response).

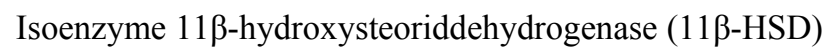
is then an important regulation factor. Cortisone conversion to cortisol is catalyzed by $11 \beta$-HSD 1 and, conversely, cortisol-to-cortisone conversion is catalyzed by $11 \beta$-HSD2.

\section{GC rhythm}

GCs production depends on circadian and circannual biorhythms. The peak of GC levels is just before the beginning of activity (in nocturnal animals at a sunset, in diurnal animals at a sunrise) while the nadir of GC levels is before sleeping (e.g. Barnett et al. 1981, Becker et al. 1985a, b, Bradbury et al. 1994, Kramer and Sothern 2001). Pigs are diurnal animals so their GCs peak production is in the morning.

Circadian rhythm develops in ontogeny; young animals have no detectable rhythm as the real onset of the rhythm comes in puberty, in pigs at the age of their 15th week (von Borell and Ladewig 1992, de Jong et al. 2000), adult animals already have fully stable rhythm (since the age of 20 weeks) (Ruis et al. 1997).

Circadian rhythm could be affected by stress situations, e.g. transport (Becker et al. 1985b), temperature discomfort (Hillmann et al. 2008, Malmkvist et al. 2009), moving (Becker et al. 1985a), social instability (Ruis et al. 1997) or surgery (e.g. Levine et al. 1980, McIntosh et al. 1981, Becker et al. 1985a).

\section{DHEA, DHEAS}

Dehydroepiandrosterone

(DHEA) and sulphate (DHEAS) are steroids that mainly originate in the adrenal cortex, to a lesser degree in neuronal brain cells (as neurosteroids), gonads or placenta. DHEA is converted to DHEAS by sulfotransferase in the adrenal cortex, liver or small intestine. DHEAS is the main circulating form; it acts as a pool of DHEA. DHEA has a wide spectrum of biological influences; it is a weak androgen, but basically it is a precursor of sex steroids, both androgens and estrogens. Both hormones have a positive effect on learning and memory. The lack of DHEA could be a cause of degenerative immune and brain changes in elderly people (Baulieu et al. 2000).

DHEA and DHEAS acts via intracellular or membrane receptors, e.g. NMDA, $\mathrm{GABA}_{\mathrm{A}}, \sigma 1$, etc. These receptors modulate memory processes (Bičíková et al. 2000). $N$-methyl $D$-aspartate (NMDA) receptors are present in many brain and CNS structures, they are important in synaptic plasticity, learning, and memory functions. Positive modulation of NMDA receptors increases inflow $\mathrm{Ca}^{2+}$ into cell and consecutive activation calcium dependent enzymes, e.g. phospholipase $\mathrm{A}_{2}$ $\left(\mathrm{PLA}_{2}\right)$. Positive modulators could be steroid hormones and their sulphate derivates - DHEA, DHEAS or pregnenolone sulphate (PregS). Positive modulation increases the excitability effect of the target cell and it improves memory functions (Bičíková et al. 2000). Another type of receptor modulated by DHEA or DHEAS is the $\gamma$-aminobutyric acid $\left(\mathrm{GABA}_{\mathrm{A}}\right)$ receptor. Compared to the NMDA receptor, DHEA and its sulphated metabolite DHEAS are negative modulators (Gartside et al. 2010).

\section{Heart catheterization}

is an invasive cardiac procedure standardly used in human medicine. The aim of our research was to study eventual circadian changes of GCs secretion in young female pigs undergoing this procedure, and to study whether this type of procedure can cause stress and/or affect a stress response due to eventual GC circadian rhythm. The study was designed to correspond to the standard catheterization pattern in human medicine as any positive findings could be then useful for planning these medical interventions in human patients.

\section{Methods}

Animals

In our experiment female pigs were used (Sus scrofa domestica), crossbred (Landrace x Large white) 
four months old with body weight from $40 \mathrm{~kg}$ to $50 \mathrm{~kg}$. The sows were too young to have a sexual cycle; we could exclude the influence of the oestrus cycle on the stress markers levels. They originated from the AGRO Jesenice, a.s., breeding farm Radějovice (RČH CZ21045103). The pigs were maintained at the farm under conventional conditions (room temperature about $20{ }^{\circ} \mathrm{C}$, humidity between 40 and $70 \%$, natural lighting and regulated ventilation). They were fed a balanced diet for fattening pigs (Čos II, Velaz, Czech Republic) in accordance with the feeding standard. Drinking water was available ad libitum. The end of sleep was determined rather by standardized time of a morning feeding than by the light regime.

Ethical note: The experiment was performed in accordance with Czech law and corresponding EU regulations and was approved by the Institutional Animal Care and Use Committee.

\section{Experiment}

23 female pigs were used, divided into two groups: 1) catheterization in the morning $(n=13)$ and $2)$ catheterization in the afternoon $(n=10)$.

\section{Heart catheterization}

The heart catheterization was bilateral (sinistral and dextral) performed using a standard catheterization procedure (through arteria and vena femoralis using 7-9F sheet). The catheterizations were carried out as part of electrophysiological projects, in which electrical stimulation and radiofrequency ablation were performed. In all tested animals of both groups four markers were assessed in the blood serum: cortisol, cortisone, DHEA and DHEAS.

\section{Anesthesia and medication}

Stresnil (azaperone, dose: $5 \mathrm{mg} / \mathrm{kg}$ ), Atropin (atropine sulphate, dose: $0.05 \mathrm{mg} / \mathrm{kg}$ ) and Narcetan (ketamine hydrochloride, dose: $14 \mathrm{mg} / \mathrm{kg}$ ) by an intramuscular injection for pre-medication and sedation were used. To obtain intravenous (IV) access an $18 \mathrm{G}$ or 20G IV cannula was inserted into the marginal ear vein. Intravenous anesthetic introduction started with Propofol (1\% propofol: dose $2 \mathrm{mg} / \mathrm{kg}$ bolus) and Morphine (1\% morphini hydrochloridum trihydricum: dose $0.2 \mathrm{mg} / \mathrm{kg}$ bolus). Intubation under direct laryngoscopic control was performed with 7 or $7.5 \mathrm{~mm}$ orotracheal tubes, depending on the size of the sow. Anesthesia was maintained with a average propofol (dose: $4 \mathrm{mg} / \mathrm{kg} / \mathrm{h}$ ) IV infusion, and as analgesic morphine (dose; $0.2 \mathrm{mg} / \mathrm{kg}$ ) IV bolus was administered every hour. Ventilation was sustained at an average volume of 8 to $10 \mathrm{ml} / \mathrm{kg}$ and respiratory rates of 15 per minute.

During the IV anesthesia a continuous monitoring of mean arterial pressure (MAP), heartbeat rate $(\mathrm{HR}), \mathrm{O}_{2}$ saturation $\left(\mathrm{SO}_{2}\right)$ and exhaled capnometry $\left(\mathrm{PCO}_{2}\right)$ was observed on a multiparameter bed-side monitor.

\section{Blood collection}

Blood was collected from the jugular vein in four defined periods of the experiment. The first (1) was collected at the farm, in non-stress domestic conditions (control sample, basal levels of the stress markers), other samples were collected 10 minutes after the presumed stress situation: the second sample (2) 10 minutes after intubation and introduction to anesthesia, the third sample (3) 10 minutes after heart stimulation or ablation and the last (4) at the end of the operation, before the animal was sacrificed. Total amount of blood $(10 \mathrm{ml})$ was collected in a $10 \mathrm{ml}$ serum Vacutainer system tube (BD Vacutainer, SSt II Advance), after 30 minutes of incubation in room temperature the tubes were centrifuged $(2000 \mathrm{x} \mathrm{g})$ for 15 minutes and then the serum was stored at $-20{ }^{\circ} \mathrm{C}$ till further analyses.

\section{Timing of the experiment}

The morning experiments were started at 9 AM, the afternoon ones at 3 PM (by premedication, one hour after sows' arrival to our laboratory). Intubation and introduction to anesthesia were performed usually half an hour after premedication, the heart catheterization itself starts one hour and ends two and half hours after premedication (then the third blood sample was obtained) and experiments ended usually three to four hours after the premedication. Note: timing could be little bit variable due to complications or unpredictable events.

\section{Laboratory analysis}

Cortisol and cortisone was assessed using the method published elsewhere (Šimůnková et al. 2008). Briefly, the serum samples were twice extracted and afterwards a high performance liquid chromatography (HPLC) system from Dionex Softron (Germering, Germany) was used for hormone separation. HPLC separation was carried out with reverse phase EC 250/4 NUCLEOSIL $®$ 100-5 C18 column (MACHEREYNAGEL, Düren, Germany). To avoid possible column 
contamination the Phenomenex SecurityGuard system with C18 cartridge (Phenomenex, Torrance, CA) was used. The solvents Merck (Darmstadt, Germany) were used as mobile phase for HPLC. Serum cortisol and cortisone concentrations were determined according to a calibration curve using UV/VIS detection.

DHEA and DHEAS were measured by commercial radioimmunoassay and immunoradiometric kits (Immunotech; Czech Division, Marseille, France). Intra-assay and inter-assay coefficients of variation (CVs) for DHEA were found below or equal to $7.9 \%$ and $11.9 \%$. Intra- and inter-assay CVs for DHEAS were below or equal to $7.4 \%$ and $10.6 \%$, respectively. The analytical parameters corresponded to those stated by the manufacturer.

\section{Statistics}

Data were divided into two groups, according to the time of day of the experiment (morning or afternoon hours). For each group there was performed an independent statistical test for evaluating elementary statistical data (median, minimum, maximum) for each marker in each period of experiment.

For testing the difference between morning and afternoon samples, a non-parametric Mann-Whitney test was performed. A non-parametric test was used since our data didn't show standard Gaussian distribution. The Mann-Whitney test was calculated for two independent samples (morning and afternoon) for each marker in each period of the experiment.

\section{Results}

Elementary statistical data were calculated for cortisol, cortisone, DHEA and DHEAS for each period of the experiment (1-4; see section Methods for details) for two different groups separately (morning and afternoon catheterization). Measured data demonstrated wide variance, indicating noticeable interindividual variation in these markers' levels (minimum and maximum values for each marker are shown in Tables 1-4). Measured concentrations in cortisone, DHEA and DHEAS were in some samples under the detection limit (minimum $0.00 \mathrm{nmol} / \mathrm{l})$.

\section{Cortisol}

For the first period of the experiment (at the farm, non-stress conditions) the median was 145.15 $\mathrm{nmol} / \mathrm{l}$ for the morning group and $154.90 \mathrm{nmol} / \mathrm{l}$ for the afternoon group. At the second period (after introduction to anesthesia) the median was $272.61 \mathrm{nmol} / 1$ in the morning and $327.75 \mathrm{nmol} / \mathrm{l}$ in the afternoon group. After conducting tissue ablation or cardiostimulation (third period) the median, minimum and maximum were quite close for both groups. The median was $231.00 \mathrm{nmol} / 1$ for the morning and $241.00 \mathrm{nmol} / 1$ for the afternoon group. The minimum concentration was $82.00 \mathrm{nmol} / \mathrm{l}$ for the morning and $105.00 \mathrm{nmol} / 1$ for the afternoon group. The maximum was $365.00 \mathrm{nmol} / 1$ for the morning and 374.68 $\mathrm{nmol} / \mathrm{l}$ for the afternoon catheterization. For the fourth section of the experiment (at the end of the catheterization) the median was $143.95 \mathrm{nmol} / 1$ in the morning and $224.00 \mathrm{nmol} / 1$ in the afternoon experiment.

We assumed diurnal variation in cortisol, but, surprisingly, we did not find it in any period of our experiment. The Mann-Whitney test for all stages was statistically non-significant in significance level 0.05 $(\mathrm{p}>0.05)$. Results are shown in Table 1 .

Table 1. Median, minimum, maximum and Mann-Whitney test for two independent samples (morning and afternoon) for cortisol levels.

\begin{tabular}{|c|c|c|c|c|c|}
\hline $\begin{array}{l}\text { Period of } \\
\text { experiment }\end{array}$ & Group & $\begin{array}{l}\text { Median } \\
(\mathrm{nmol} / \mathrm{l})\end{array}$ & $\begin{array}{l}\text { Minimum } \\
\text { (nmol/l) }\end{array}$ & $\begin{array}{l}\text { Maximum } \\
\text { (nmol/l) }\end{array}$ & $\mathbf{p}$ \\
\hline \multirow[t]{2}{*}{1} & morning & 145.15 & 58.11 & 716.71 & 0.55 \\
\hline & afternoon & 154.90 & 121.00 & 445.53 & \\
\hline \multirow[t]{2}{*}{2} & morning & 272.61 & 58.00 & 394.22 & 0.14 \\
\hline & afternoon & 327.75 & 118.00 & 435.34 & \\
\hline \multirow[t]{2}{*}{3} & morning & 231.00 & 82.00 & 365.00 & 0.58 \\
\hline & afternoon & 241.82 & 105.00 & 374.68 & \\
\hline \multirow[t]{2}{*}{4} & morning & 143.95 & 50.34 & 405.69 & 0.20 \\
\hline & afternoon & 224.00 & 122.11 & 396.00 & \\
\hline
\end{tabular}


Table 2. Median, minimum, maximum and Mann-Whitney test for two independent samples (morning and afternoon) for cortisone levels.

\begin{tabular}{llllll}
\hline $\begin{array}{l}\text { Period of } \\
\text { experiment }\end{array}$ & Group & $\begin{array}{l}\text { Median } \\
(\mathbf{n m o l} / \mathbf{l})\end{array}$ & $\begin{array}{l}\text { Minimum } \\
(\mathbf{n m o l} / \mathbf{l})\end{array}$ & $\begin{array}{l}\text { Maximum } \\
(\mathbf{n m o l} / \mathbf{l})\end{array}$ & $\mathbf{p}$ \\
\hline 1 & & 2.93 & 0.00 & 52.00 & 0.32 \\
2 & $\begin{array}{l}\text { morning } \\
\text { afternoon }\end{array}$ & 8.16 & 0.00 & 55.53 & 0.52 \\
3 & morning & 28.36 & 16.68 & 94.56 & \\
& afternoon & 76.50 & 13.00 & 151.31 & 0.15 \\
4 & morning & 35.67 & 15.25 & 204.00 & 0.15 \\
& afternoon & 127.79 & 20.93 & 290.00 & 363.77 \\
\hline
\end{tabular}

Table 3. Median, minimum, maximum and Mann-Whitney test for two independent samples (morning and afternoon) for DHEA levels.

\begin{tabular}{llllll}
\hline $\begin{array}{l}\text { Period of } \\
\text { experiment }\end{array}$ & Group & $\begin{array}{l}\text { Median } \\
(\mathbf{n m o l} / \mathbf{l})\end{array}$ & $\begin{array}{l}\text { Minimum } \\
(\mathbf{n m o l} / \mathbf{l})\end{array}$ & $\begin{array}{l}\text { Maximum } \\
(\mathbf{n m o l} / \mathbf{l})\end{array}$ & $\mathbf{p}$ \\
\hline 1 & morning & 0.19 & 0.00 & 0.76 & 0.59 \\
2 & afternoon & 0.12 & 0.00 & 0.53 & 0.47 \\
3 & morning & 0.58 & 0.44 & 1.40 & 0.54 \\
4 & afternoon & 0.57 & 0.33 & 0.93 & 0.31 \\
& morning & 0.69 & 0.52 & 2.12 & 0.30 \\
\hline
\end{tabular}

\section{Cortisone}

For the first section of the experiment the median was $2.93 \mathrm{nmol} / \mathrm{l}$ for the morning group and $8.16 \mathrm{nmol} / 1$ for the afternoon group. After introduction to anesthesia the median was $28.36 \mathrm{nmol} / 1$ in the morning and $76.50 \mathrm{nmol} / 1$ in the afternoon group. For the third section the median was $35.67 \mathrm{nmol} / 1$ for the morning and $127.79 \mathrm{nmol} / \mathrm{l}$ for the afternoon group. At the end of the operation (fourth period) the median was $19.00 \mathrm{nmol} / \mathrm{l}$ in the morning and $124.62 \mathrm{nmol} / \mathrm{l}$ in the afternoon experiment.

Results for the Mann-Whitney test were statistically non-significant $(p>0.05)$ in all stages of catheterization; there is no diurnal variation in cortisone levels. Results are shown in Table 2.

\section{DHEA}

For the farm sample the median was $0.19 \mathrm{nmol} / 1$ for the morning group and $0.12 \mathrm{nmol} / 1$ for the afternoon group. At the second section of the catheterization the median was $0.58 \mathrm{nmol} / 1$ in the morning and $0.57 \mathrm{nmol} / 1$ in the afternoon group. For the third period of the experiment the median was $0.69 \mathrm{nmol} / 1$ for the morning and $0.74 \mathrm{nmol} / 1$ for the afternoon group. At the end of experiment the median was $0.90 \mathrm{nmol} / \mathrm{l}$ in morning and $0.61 \mathrm{nmol} / \mathrm{l}$ in the afternoon experiments. Medians for all tested stages were very close in both groups.

The Mann-Whitney test for DHEA was statistically non-significant $(p>0.05)$ in all periods of the experiment; there are no diurnal variations in the DHEA levels. Results are shown in Table 3.

\section{DHEAS}

For the first stage of the experiment the median was $0.01 \mathrm{nmol} / 1$ for the morning group and $0.11 \mathrm{nmol} / 1$ for the afternoon group. After introduction to anesthesia the median was $0.83 \mathrm{nmol} / 1$ in the morning and $0.10 \mathrm{nmol} / 1$ in the afternoon group. At the third stage the median was $0.65 \mathrm{nmol} / 1$ for the morning and $0.10 \mathrm{nmol} / 1$ for the afternoon group. At the end of catheterization the 
median was $0.11 \mathrm{nmol} / 1$ in the morning and $0.13 \mathrm{nmol} / 1$ in the afternoon experiment.

The Mann-Whitney test was non-significant at the significance level of 0.05 in all stages of experiment $(\mathrm{p}>0.05)$, there are no diurnal variation in DHEAS levels. Results are shown in Table 4.

Table 4. Median, minimum, maximum and Mann-Whitney test for two independent samples (morning and afternoon) for DHEAS levels.

\begin{tabular}{llllll}
\hline $\begin{array}{l}\text { Period of } \\
\text { experiment }\end{array}$ & Group & $\begin{array}{l}\text { Median } \\
(\mathbf{n m o l} / \mathbf{l})\end{array}$ & $\begin{array}{l}\text { Minimum } \\
(\mathbf{n m o l} / \mathbf{l})\end{array}$ & $\begin{array}{l}\text { Maximum } \\
(\mathbf{n m o l} / \mathbf{l})\end{array}$ \\
\hline \multirow{2}{*}{$\begin{array}{l}\text { morning } \\
\text { afternoon }\end{array}$} & 0.01 & 0.00 & 0.14 & 0.31 \\
2 & 0.11 & 0.00 & 0.14 & 0.38 \\
& morning & 0.83 & 0.02 & 0.18 & 0.26 \\
4 & afternoon & 0.10 & 0.00 & 0.23 & 0.32 \\
& morning & 0.65 & 0.00 & 0.20 & 0.40 \\
& afternoon & 0.10 & 0.07 & 0.19 & 0.25 \\
\hline
\end{tabular}

\section{Discussion}

The aim of the presented study was to find out the circadian rhythm and its eventual changes of cortisol, cortisone, DHEA and DHEAS in young (12 weeks old) female pigs when undergoing standard heart catheterization (stress load). Pigs were chosen because many metabolic and chronobiological similarities with people. In fact, similar experiment could be technically well realized on human patients as well, but the experiment requires to collect several times relatively big volumes of blood (one sample has to contain at least $10 \mathrm{ml}$ of blood), what could be in seriously ill people an unpleasant ethical problem. It is well known that pigs have circadian rhythm of cortisol (e.g. Barnett et al. 1981, Becker et al. 1985a, b, Griffith and Minton 1991). Pigs are animals with diurnal biorhythm, which is why we expected higher levels of GC in the morning than in the afternoon experiments. No circadian rhythm in GCs was found at any period of the experiment; this could result from numerous causes. We can divide the causes into two groups: (1) non-stress and (2) stress reasons, and the second group to subgroups: a) moving to another pen and consecutive stress from social isolation, b) fasting, c) transport from home farm to experimental lab, d) the heart catheterization.

We had young (12 weeks old) female pigs in our experiment, which could be the first, stress-independent reason for the absence of circadian variation in cortisol in our experimental animals. Our findings also correspond to some papers (e.g. von Borell and Ladewig 1992, Ruis et al. 1997, de Jong et al. 2000) that demonstrated the absence of cortisol circadian rhythm in pigs younger than 15 weeks old. According to these studies, a stable circadian rhythm is aimed only at the age of 20 weeks, with a peak in the morning and a nadir in the evening (Ruis et al. 1997, de Jong et al. 2000). On the other hand, Ekkel et al. (1996) found contradictory findings: circadian rhythm was present in 8-weeks-old piglets.

The second group, stress reasons, is more complex. It was proved that elevated GC levels could affect and disrupt circadian rhythms (references in following text). A stressor could be anything that disturbs welfare or homeostasis and that could activate the HPA axis (Janssens et al. 1994, Pol et al. 2002). Animals living on a farm are transported to our laboratory one hour before premedication on the day of the experiment; the possible stressors are very numerous: moving to another pen, social stress (social isolation), feeding absence, and the transport itself. On the home farm, the pigs were used to living in natural social groups. The day before the transport to our lab, the experimental pig was separated from its home pen to another pen, where it was alone without social mates. There can be a source of stress from moving and social stress. The pig was suddenly in unknown territory without other members of its social group, without familiar smells, etc. Both moving and exposure to a new territory (Dantzer and Morméde 1983, Becker et al. 1985a, Grandin 1997, Désautés et al. 1999) and social instability, few or no social contacts (Janssens et al. 1994, Ekkel et al. 1997, Ruis et al. 1997) could elevate GCs levels. On the 
contrary, Geverink et al. (2003) found higher GCs concentrations in females housed in groups than alone, but these group-housed pigs had less circadian amplitude GCs levels. Janssens et al. (1995) demonstrated impaired circadian rhythms after chronic social stress, which was not the case in our experiment, but many procedures used could cause acute stress. Moving experiments were carried out by Becker et al. (1985a) and they have proved that moving can disrupt diurnal rhythm. Moreover, the same effect can result from social frustration (Barnett et al. 1994, Ruis et al. 1997).

The day before the experiment, after moving, the pig had to fast (due to anesthesia performed the next day). Food intake can influence circadian rhythm. In some studies two peaks of corticosteroid levels were found, in the morning and in the afternoon, which was the time when the animals expected to be fed (Geverink et al. 2003, Hillmann et al. 2008). On the other hand, Barnett et al. (1981) didn't find any afternoon peak, but fully confirmed the morning one. Fasting is a stressful event, which can also affect circadian rhythm.

Transport from the farm to the laboratory is another stressful event that could cause elevated corticosteroids levels (e.g. Becker et al. 1985b, Dalin et al. 1993, Averos 2007). Higher cortisol levels were found in females than in males, in winter than in summer and in longer transports (Averos 2007).

Heart catheterization is a minimally invasive intervention, but many studies didn't find differences in elevated GC levels between invasive open surgery and minimally invasive procedures in pigs (Mansour et al. 1992, Bessler et al. 1994, Burpee et al. 2002, Margulis et al. 2005, Matsumoto et al. 2005, Duchene et al. 2008). This means that even minimal intervention can cause a rise in GC levels and consecutive instability in circadian level. But stress response to surgery can be modulated by some other parameters, e.g. type of anesthesia, hurtfulness, etc. (Marana et al. 2008). Particularly numerous anesthetics (including Ketamine) can influence some diurnal rhythms: melatonin secretion in rabbits (Pang et al. 2001), cortisol level and appetite in macaques (Crockett et al. 2000) or mesors, amplitudes and acrophases of heart rate, body temperature and locomotor activity in rats (Prudian et al. 1997).

Nevertheless, we assume that absent cortisol circadian rhythm in our experimental young pigs was caused particularly by the immaturity of the hypothalamo-pituitary-adrenal (HPA) axis. Moreover, circadian rhythm could be theoretically affected by the procedures held on the day before the experiment (moving, social deprivation, fasting), but no difference was found between GCs levels during the whole catheterization procedure and the basal value of GCs levels from the preceding evening (Skarlandtová et al. 2011). The heart catheterization could influence circadian rhythm, but the time of acute stress is relatively too short time to affect the whole rhythm. Cortisol/cortisone ratio indicates that pigs are not in a stress; even during intervention (Skarlandtová et al. unpublished data). However, in stress studies it is important to monitor not only GCs levels, but also the circadian rhythm (de Jong et al. 2000).

The concentration of DHEA and DHEAS is higher in stress events, as cortisol concentration (e.g. Nieschlag et al. 1973). These steroids have antiglucocorticoid effect, they acts as "antistress" steroids and minimize negative glucocorticoid effects (e.g. Kimonides et al. 1998, 1999, Charney 2004, Maninger 2009). As cortisol, DHEA and DHEAS have circadian variability with the highest levels in the morning and the nadir in the evening. In our experiment, there were no differences between morning and afternoon levels of these steroids. Because the process of concentration elevation of DHEA and DHEAS acts in the same way as in cortisol elevation, we could assume, our experimental sows are too young to have stable circadian rhythm in DHEA and DHEAS, because of the immaturity of the HPA axis.

\section{Conclusion}

Our experiments surprisingly revealed minimal changes $(p>0.05)$ in tested markers during heart catheterization in the morning when compared to the afternoon hours in each period of the experiment in any marker (cortisol, cortisone, DHEA and DHEAS). This means that morning and afternoon levels are not different; our results have not proved any diurnal rhythm or variation in GCs production in the studied group of experimental animals, but the results have also suggested that there is no difference in the stress load between morning and afternoon catheterization. Consequently, we can assume that there is no diurnal variation in the stress markers levels under the stress load and that timing is not a limiting factor for the elective cardiac interventional procedure.

\section{Conflict of Interest}

There is no conflict of interest. 


\section{Acknowledgements}

This study was supported by grant no. 259223118209 of the Grant Agency of the Charles University of Prague (GA UK). The authors would like to thank Bortelová J., Červenková J., Ehrlichová A., Kypta K. and
Vavř́iková T. for their technical support and kind help during the experiments at the Cardiac Electrophysiology Experimental Laboratory ( $\mathrm{Na}$ Homolce Hospital and First Faculty of Medicine, Charles University in Prague).

\section{References}

AVEROS X, HERRANZ A, SANCHEZ R, COMELLA JX, GOSALVEZ LF: Serum stress parameters in pigs transported to slaughter under commercial conditions in different seasons. Vet Med 52: 333-342, 2007.

BARNETT JL, WINFIELD CG, CRONIN GM, MAKIN AW: Effects of photoperiod and feeding on plasma corticosteroid concentrations and maximum corticosteroid-binding capacity in pigs. Aust J Biol Sci 34: 577$585,1981$.

BAULIEU EE, THOMAS G, LEGRAIN S, LAHLOU N, ROGER M, DEBUIRE B, FAUCONEAU V, GIRARD L, HERVY M-P, LATOUR F, LEAUD M-C, MOKRANE A, PITTI-FERRANDI H. TRIVALLE C, DE LACHARRIERE O, NOUVEAU S, RAKOTO-ARISON B, SOUBERBIELLE J-C, RIAON J, LE BOUC Y, RAYNAUD A, GIRERED X, FORETTE F: Dehydroepiandrosterone (DHEA), DHEA sulfate, and aging: contribution of the DHEAge Study to a sociobiomedical issue. Proc Natl Acad Sci USA 97: 42794284, 2000.

BECKER BA, FORD JJ, CHRISTENSON RK, MANAK RC, HAHN GL, DESHAZER JA: Cortisol response of gilts in tether stalls. J Anim Sci 60: 264-270, 1985a.

BECKER BA, NIENABER JA, DESHAZER JA, HAHN GL: Effect of transportation on cortisol concentrations and on the circadian rhythm of cortisol in gilts. Am J Vet Res 46: 1457-1459, $1985 \mathrm{~b}$.

BESSLER M, WHELAN RL, HALVERSON A, TREAT MR, NOWYGROD R: Is immune function better preserved after laparoscopic versus open colon resection? Surg Endosc 8: 881-883, 1994.

BIČÍKOVÁ M, TALLOVÁ J, HILL M, KRAUSOVÁ Z, HAMPL R: Serum concentrations of some neuroactive steroids in women suffering from mixed anxiety-depressive disorder. Neurochem Res 25: 1623-1627, 2000.

BRADBURY MJ, AKANA SF, DALLMAN MF: Roles of type I and II corticosteroid receptors in regulation of basal activity in the hypothalamo-pituitary-adrenal axis during the diurnal trough and the peak: evidence for a nonadditive effect of combined receptor occupation. Endocrinology 134: 1286-1296, 1994.

BREUNER CW, ORCHINIK M: Beyond carrier proteins. Plasma binding proteins as mediators of corticosteroid action in vertebrates. $J$ Endocrinol 175: 99-112, 2002.

BURPEE SE, KURIAN M, MURAKAME Y, BENEVIDES S, GAGNER M: The metabolic and immune response to laparoscopic versus open liver resection. Surg Endosc 16: 899-904, 2002.

CHARNEY DS: Psychobiological mechanisms of resilience and vulnerability: implications for successful adaptation to extreme stress. Am J Psychiatry 161: 195-216, 2004.

CROCKETT CM, SHIMOJI M, BOWDEN DM: Behavior, appetite, and urinary cortisol responses by adult female pigtailed macaques to cage size, cage level, room change, and ketamine sedation. Am J Primatol 52: 63-80, 2000.

DALIN AM, MAGNUSSON U, HÄGGENDAL J, NYBERG L: The effect of transport stress on plasma levels of catecholamines, cortisol, corticosteroid-binding globulin, blood cell count, and lymphocyte proliferation in pigs. Acta Vet Scand 34: 59-68, 1993.

DANTZER R, MORMÈDE P: Stress in farm animals: a need for re-evaluation. J Anim Sci 57: 6-18, 1983.

DE JONG IC, PRELLE IT, VAN DE BURGWAL JA, LAMBOOIJ E, KORTE SM, BLOKHUIS HJ, KOOLHAAS JM: Effects of environmental enrichment on behavioral responses to novelty, learning, and memory, and the circadian rhythm in cortisol in growing pigs. Physiol Behav 68: 571-578, 2000.

DÉSAUTÉS C, SARRIEAU A, CARITEZ JC, MORMÈDE P: Behavior and pituitary-adrenal function in large white and Meishan pigs. Domest Anim Endocrinol 16: 193-205, 1999.

DESBOROUGH JP: The stress response to trauma and surgery. Br J Anaesth 85: 109-117, 2000. 
DUCHENE DA, GALLAGHER BL, RATLIFF TL, WINFIELD HN: Systemic and cell-specific immune response to laparoscopic and open nephrectomy in porcine model. J Endourol 22: 113-120, 2008.

EKKEL ED, DIELEMAN SJ, SCHOUTEN WGP, PORTELA A, CORNÉLISSEN G, TIELEN MJM, HALBERG F: The circadian rhythm of cortisol in the saliva of young pigs. Physiol Behav 60: 985-989, 1996.

EKKEL ED, SAVENIJE B, SCHOUTEN WGP, WIEGANT VM, TIELEN MJM: The effects of mixing on behavior and circadian parameters of salivary cortisol in pigs. Physiol Behav 62: 181-184, 1997.

GARTSIDE SE, GRIFFITH NC, KAURA V, INGRAM CD: The neurosteroid dehydroepiandrosterone (DHEA) and its metabolites alter 5-HT neuronal activity via modulation of $\mathrm{GABA}_{\mathrm{A}}$ receptors. J Psychopharmacol 24: 1717 $1724,2010$.

GEVERINK NA, SCHOUTEN WGP, GORT G, WIEGANT VM: Individual differences in behaviour, physiology and pathology in breeding gilts housed in groups or stalls. Appl Anim Behav Sci 81: 29-41, 2003.

GRANDIN T: Assessment of stress during handling and transport. J Anim Sci 75: 249-257, 1997.

GREENBERG N, CARR JA, SUMMERS CH: Ethological cause and consequences of the stress response. Integr Comp Biol 42: 508-516, 2002.

GRIFFITH MK, MINTON JE: Free-running rhythms of adrenocorticotropic hormone (ACTH), cortisol and melatonin in pigs. Domest Anim Endocrinol 8: 201-208, 1991.

HILLMANN E, SCHRADER L, MAYER C, GYGAX L: Effects of weight, temperature and behaviour on the circadian rhythm of salivary cortisol in growing pigs. Animal 2: 405-409, 2008.

JANSSENS CJJG, HELMOND FA, WIEGANT VM: The effect of chronic stress on plasma cortisol concentrations in cyclic female pigs depends on the time of day. Domest Anim Endocrinol 12: 167-177, 1995.

JANSSENS CJJG, HELMOND FA, WIEGANT VM: Increased cortisol response to exogenous adrenocorticotropic hormone in chronically stressed Pigs: influence of housing conditions. J Anim Sci 72: 1771-1777, 1994.

KIMONIDES VG, KHATIBI NH, SVENDSEN CN, SOFRONIEW MV, HERBERT J: Dehydroepiandrosterone (DHEA) and DHEA-sulfate (DHEAS) protect hippocampal neurons against excitatory amino acid-induced neurotoxicity. Proc Natl Acad Sci USA 95: 1852-1857, 1998.

KRAMER KM, SOTHERN RB: Circadian characteristics of corticosterone secretion in red-backed voles (Clethrionomys gapperi). Chronobiol Int 18: 933-945, 2001.

LEVINE RL, MCINTOSH TK, LOTHROP DA, JACKSON BT: Circadian periodicity of plasma corticosterone levels in rats subjected to hemorrhagic shock and surgical trauma. Horm Res 13: 385-395, 1980.

MALMKVIST J, DAMGAARD BM, PEDERSEN LJ, JØRGENSEN E, THODBERG K, CHALOUPKOVÁ H, BRUCKMAIER RM: Effects of thermal environment on hypothalamic-pituitary-adrenal axis hormones, oxytocin, and behavioral activity in periparturient sows. J Anim Sci 87: 2796-2805, 2009.

MANINGER N, WOLKOWITZ OM, REUS VI, EPEL ES, MELLON SH: Neurobiological and neuropsychiatric effects of dehydroepiandrosterone (DHEA) and DHEA sulfate (DHEAS). Front Neuroendocrinol 30: 65-91, 2009.

MANSOUR MA, STIEGMANN GV, YAMAMOTO M, BERGUER R: Neuroendocrine stress response after minimally invasive surgery in pigs. Surg Endosc_6: 294-297, 1992.

MARANA E, SCAMBIA G, COLICCI S, MAVIGLIA R, MAUSSIER ML, MARANA R, PROIETTI R: Leptin and perioperative neuroendocrine stress response with two different anaesthetic techniques. Acta Anaesthesiol Scand 52: 541-546, 2008.

MARGULIS V, MATSUMOTO ED, TUNC L, TAYLOR G, DUCHENNE D, CADEDDU JA: Effect of warmed, humidified insufflation gas and anti-inflammatory agents on cytokine response to laparoscopic nephrectomy: porcine model. J Urol 174: 1452-1456, 2005.

MATSUMOTO ED, MARGULIS V, TUNC L, TAYLOR GD, DUCHENE D, JOHNSON DB, PEARLE MS, CADEDDU JA: Cytokine response to surgical stress: comparison of pure laparoscopic, hand-assisted laparoscopic, and open nephrectomy. J Endourol 19: 1140-1145, 2005.

MCINTOSH TK, LOTHROP DA, LEE A, JACKSON BT, NABSETH D, EGDAHL RH: Circadian rhythm of cortisol is altered in postsurgical patients. J Clin Endocrinol Metab 53: 117-122, 1981.

MÖSTL E, PALME R: Hormones as indicators of stress. Domest Anim Endocrinol 23: 67-74, 2002. 
NIESCHLAG E, LORIAUX DL, RUDER HJ, ZUCKER IR, KIRSCHNER MA, LIPSETT MB: The secretion of dehydroepiandrosterone and dehydroepiandrosterone sulphate in man. J Endocrinol 57: 123-134, 1973.

ORCHINIK M: Glucocorticoids, stress, and behavior: shifting the timeframe. Horm Behav 34: 320-327, 1998.

PANG CS, MULNIER C, PANG SF, YANG JC: Effects of halothane, pentobarbital and ketamine on serum melatonin levels in the early scotophase in New Zealand white rabbits. Biol Signals Recept 10: 310-316, 2001.

POL F, COURBOULAY V, COTTE JP, MARTRENCHAR A, HAY M, MORMÈDE P: Urinary cortisol as an additional tool to assess the welfare of pregnant sows kept in two types of housing. Vet Res 33: 13-22, 2002.

PRUDIAN F, GANTENBEIN M, PELISSIER AL, BRUGUEROLLE B: Daily rhythms of heart rate, temperature and locomotor activity are modified by anaesthetics in rat: a telemetric study. Naunyn Schmiedebergs Arch Pharmacol 355: 774-778, 1997.

ROMERO LM: Physiological stress in ecology: lessons from biomedical research. Trends Ecol Evol 19: 249-255, 2004.

RUIS MAW, TE BRAKE JHA, ENGEL B, EKKEL ED, BUIST WG, BLOKHUIS HJ, KOOLHAAS JM. The circadian rhythm of salivary cortisol in growing pigs: effects of age, gender, and stress. Physiol Behav 62: 623-630, 1997.

SCHREIBER V: Stressors. In: Stress. Pathophysiology - Endocrinology - Clinics. (in Czech) SCHREIBER V (ed), Avicenum, Praha, 1985, pp 18-21.

SECKL JR: 11beta-hydroxysteroid dehydrogenase in the brain: a novel regulator of glucocorticoid action? Front Neuroendocrinol 18: 49-99, 1997.

SELYE H: A syndrome produced by diverse nocuous agents. Nature 138: 32, 1936.

ŠIMU゚NKOVÁ K, STÁRKA L, HILL M, KŘÍŽ L, HAMPL R, VONDRA K: Comparison of total and salivary cortisol in a low-dose ACTH (Synacthen) test: influence of three-month oral contraceptives administration to healthy women. Physiol Res 57: 193-199, 2008.

SKARLANDTOVÁ H, BIČÍKOVÁ M, NEUŽIL P, MLČEK M, HRACHOVINA V, SVOBODA T, MEDOVÁ E, KUDLIČKA J, DOHNALOVÁ A, HAVRÁNEK Š, KAZIHNÍTKOVÁ H, MÁČOVÁ L, KITTNAR O: Is there circadian variation in cortisol levels in young sows in heart catheterization? Prague Med Rep 112: 184$192,2011$.

VON BORELL E, LADEWIG J: Relationship between behaviour and adrenocortical response pattern in domestic pigs. Appl Anim Behav Sci 34: 195-206, 1992. 